\title{
Waltencir Alves de Oliveira - $O$ gosto dos extremos: tensão e dualidade na poesia de João Cabral de Melo Neto, de Pedra do Sono a Andando Sevilha
}

São Paulo: Edusp; Fapesp, 2012

Solange Fiuza Cardoso Yokozawa ${ }^{1}$

João Cabral de Melo Neto, como todo grande artista, foi o primeiro crítico dele mesmo. Como é frequente nesses casos, terminou estabelecendo paradigmas de leitura que orientaram e orientam sua recepção crítica. Mas Cabral se releu e reconsiderou elementos caracterizadores de sua poesia, como o faz no poema "Dúvidas apócrifas de Marianne Moore", do livro Agrestes (1985), em que questiona o caráter anticonfessional da poesia objetiva. Também, reformulou sua obra criativa, tendo o poeta antilírico, que evitou falar de si, escrito a autobiografia poética A escola das facas (1980) e Sevilha andando (1989), livro que centraliza a amada e o amor, temas líricos por excelência. Entretanto, a crítica canônica e a crítica recente nem sempre tiveram a mesma acuidade do poeta ou atentaram para a reorientação dessa poesia, de modo que algumas chaves de leitura são usadas para caracterizar de maneira geral a obra cabralina, sem as problematizações e as relativizações necessárias. Nesse sentido, um livro como $O$ gosto dos extremos: tensão e dualidade na poesia de João Cabral de Melo Neto, de Pedra do Sono a Andando Sevilha, de Waltencir de Oliveira, publicado em 2012, pela Edusp/Fapesp, merece a atenção dos profissionais das letras e, particularmente, dos interessados na poesia de Cabral.

O livro foi apresentado inicialmente como tese de doutorado, defendida em 2008, na USP. Nele, o autor reavalia a fortuna crítica do poeta e analisa a pertinência de alguns rótulos nela impressos no confronto com a obra completa de João Cabral, propondo matizar certas chaves críticas e confrontar-lhes a pertinência para ler a poesia cabralina posterior a A educação pela pedra (1966).

Observa o crítico que os estudos canônicos sobre Cabral se fizeram do final dos anos 1960 até o começo da década de 1980, enquanto a obra

\footnotetext{
${ }^{1}$ Professora de literatura brasileira da Universidade Federal de Goiás (UFG), Goiás, GO, Brasil. Pós-doutoranda da Faculdade de Letras da Universidade de Porto (FLUP), Porto, Portugal. Bolsista do CNPq. E-mail: solfiuza@gmail.com
} 
do poeta foi encerrada em 1993 (na verdade, Sevilha andando, último livro de poemas inéditos publicado em vida pelo poeta, é de 1989), de modo que os contornos de sua poesia foram definidos pela crítica antes que se fixassem por completo, deixando de fora os seis últimos livros. Nota, também, que esses estudos constituem leituras vincadas por uma motivação teórica e crítica historicamente definida, notadamente estruturalista ou historiográfica. Além disso, pondera que os trabalhos mais recentes limitam-se, sobretudo, a consolidar e aplicar os estudos anteriores em lugar de com eles estabelecer um diálogo mais produtivo.

A proposta é arrojada e instigante e supera as expectativas quando temos em vista o nível de muitas teses defendidas anualmente no Brasil e a "zona de conforto" em que tende a operar parte considerável da inteligência nacional no campo das Letras, pouco afeita ao diálogo efetivamente produtivo com outros críticos.

Pontos altos do livro, desenvolvido ao longo de quatro capítulos, são os capítulos dois e três, em que o autor matiza a recepção crítica de Cabral a partir de dois marcos de leitura: a figuração do amor e da mulher e a representação do autobiográfico. No primeiro caso, contrariando o lugar cristalizado de que a partir do Quaderna (1960) a mulher é convertida em tema da poesia cabralina, o autor mostra como esse tema assume uma dimensão progressiva e processual desde Pedra do sono (1942). Além disso, chama a atenção para o fato de a crítica considerar sobremaneira a autorreferencialidade de um livro como Os três mal amados (1943), desconsiderando o elemento amoroso que o move desde o título. Não se pode deixar de notar que, se a mulher, como sustenta o crítico, figura desde a obra inaugural de Cabral, entretanto, somente em Quaderna ela é representada segundo um modus operandi reconhecivelmente cabralino. Em se tratando do autobiográfico, observa o crítico como a impessoalidade cabralina pode ser confrontada em um livro como A escola das facas, em que o poeta opta por um gênero que centraliza a experiência pessoal.

O principal lugar-comum da crítica posto em xeque ao longo dos quatro capítulos que compõem o livro, mormente nos capítulos dois e quatro, é a divisão da poesia cabralina em duas águas. Trata-se de divisão proposta pelo próprio Cabral entre seus livros quando, em 1956, reuniu sua obra e, seguindo uma sugestão de Aníbal Machado, intitulou-a Duas águas. Na orelha não assinada do livro e provavelmente escrita pelo próprio poeta, duas águas não correspondem a poemas herméticos e 
poemas claros ou a poemas mais ou menos formalmente construídos, mas a duas intenções do autor e, consequentemente, a dois modos de recepção, ou seja, poemas destinados à leitura silenciosa de gabinete e poemas para serem lidos em voz alta para um público mais amplo.

A diferença é interessante na medida em que revela a consciência de Cabral em relação à vocalização do poema como estratégia de comunicação numa época em que já havia identificado, na conferência "Da função moderna da poesia", proferida em 1954, no Congresso de Poesia de São Paulo, um forte alheamento individualista da poesia. Mas essa divisão teria dado margens a equívocos críticos, que a fundamentam em outros critérios que não os previstos inicialmente pelo poeta. Waltencir de Oliveira procura discutir esses equívocos, relativizando, inclusive, o próprio critério da comunicabilidade estabelecido por Cabral e desenvolvido por Benedito Nunes. Nesse sentido, tendo em vista as pesquisas de Paul Zumthor, defende que a comunicabilidade é antes decorrência da recepção do que da produção. As considerações são instigantes porque, de fato, há muitas variáveis para que haja um encontro feliz entre um texto e um público mais horizontal.

Ao defender que a comunicabilidade depende de uma estética do efeito e não de uma estética da produção, Waltencir de Oliveira propõe dialogar antiteticamente com críticos como Haroldo de Campos, João Alexandre Barbosa e Benedito Nunes, que, segundo ele, "deixam de aceitar o caráter histórico e social dos processos de recepção que tornam uma obra comunicativa em dado contexto, creditando ao contrário, a maior ou menor comunicabilidade do texto a aspectos imanentes e inscritos neles" (p. 146).

O crítico tem razão ao relativizar critérios intrínsecos como responsáveis pela comunicação de um texto, como podemos testar recorrendo a exemplos outros que não os comentados. O poema-livro $O$ rio (1954), que tenta responder, como realização criativa, às preocupações críticas com o leitor sintetizadas na conferência “ $\mathrm{Da}$ função moderna da poesia" e que parece mais legível ao leitor mediano, paradoxalmente, não está entre as peças cabralinas mais conhecidas. Curiosamente, um poema cuja elaboração custou anos de trabalho ao poeta e que apresenta uma tecedura complexa, como é o caso de "Tecendo a manhã", de A educação pela pedra, caiu no gosto público, sendo literalmente usado como poema tema do trabalho coletivo. Também tem razão o crítico ao colocar em evidência a comunicação da 
poesia, tendo em vista o papel de "canais", como a montagem teatral e a televisão. Mas se equivoca ao rechaçar os critérios intrínsecos e creditar a responsabilidade da difusão pública de uma obra como Morte e vida severina sobretudo a critérios extrínsecos, como a montagem teatral. A divulgação de um texto literário por meio do teatro ou da televisão pode concorrer para a popularização desse texto, o que comprova a suposição do próprio Cabral, na conferência de 1954, de que os meios modernos de comunicação de massa poderiam contribuir para minorar o abismo que separa a poesia do grande público. Mas não se pode refutar o maior apelo público de determinadas obras, que Morte e vida severina (1956) é em si uma obra mais comunicativa do que um poema como Uma faca só lâmina (1956). Se uma montagem de Morte e vida severina é um sucesso público e outra, um fracasso, se uma performance televisiva pode comunicar ao leitor poemas formalmente tensos como os de A educação pela pedra, isso, entretanto, a despeito do que o crítico quer fazer supor, não invalida a fatura mais comunicativa do poema dramático ou faz do livro de 1966 uma obra de grande público. Além disso, o fato de um elemento de composição, como o aproveitamento da oralidade, não responder sozinho pela maior sensibilização pública de uma obra, não implica, como entende Waltencir de Oliveira, que esse elemento, quando combinado com outros, não possa assumir um apelo público em determinados textos. Há uma rede complexa de fatores, tanto intrínsecos quanto extrínsecos, tanto da ordem da produção quando da ordem da recepção, que respondem pelo sucesso público de uma obra, redundando em simplificação creditá-lo preponderantemente a fatores ligados ao momento da recepção.

Mas esses e outros questionamentos suscitados pelo livro apenas evidenciam tratar-se de obra de interesse, que suscita o diálogo crítico, não denotando pontos cegos.

Os pontos cegos do livro são devidos a outros motivos. Um deles é decorrente de uma certa tendência do autor em nem sempre ler com o cuidado e a justeza necessários os críticos com que dialoga ou em não considerar um pensamento crítico na inteireza de sua construção, o que pode ser consequência de um afã em comprovar uma hipótese em relação às leituras canônicas da poesia cabralina. Isso resulta em equívocos e omissões injustificáveis. No primeiro caso, por exemplo, há equívocos pontuais de leitura, como quando o autor, talvez movido pelo propósito de mostrar que a crítica canônica desconsidera a 
figuração do amor e da mulher nas obras anteriores a Quaderna, diz que Haroldo de Campos supervaloriza um livro como Os três mal amados em função de sua natureza autorreferencial, enquanto o crítico, caso se equivoque, é, na verdade, por desmerecer esse poema dramático, tendo escrito, em "O geômetra engajado", que essa obra representa uma "incursão sem maior importância no poema dialogado" (Campos, 2004, p. 80). Em se tratando das omissões, o autor, talvez imbuído do propósito de desconstruir um certo reducionismo na fortuna crítica de Cabral em relação à divisão de sua obra em duas águas, deixa de considerar um ensaio como "A poesia crítica de João Cabral", de João Alexandre Barbosa. Nesse pequeno trabalho, publicado na revista Cult em dezembro de 1999 e, posteriormente, reunido no livro Alguma crítica (2002), observa o autor que Cabral, ao optar, no "tríptico do Capibaribe", por uma poesia transitiva, que comunica determinada realidade social, não perde de vista a intransitividade, a crítica da própria linguagem usada para nomear essa realidade, o que é exemplar do modo tenso, dialético como João Alexandre entende a articulação cabralina entre poesia crítica e crítica de uma dada realidade social, afastando-se de qualquer visão dicotômica e reducionista dessa poesia. Waltencir de Oliveira fica sobremaneira preso ao livro tese de 1975, o A imitação da forma, deixando de fora outras publicações desse crítico que encontrou na poesia de João Cabral obsessão crítica para uma vida inteira e que, mesmo no livro de 1975, não deixa de perceber a tensa convivência dos extremos nessa poesia.

Além da ausência de outros trabalhos de João Alexandre Barbosa, tendo em vista o propósito do livro de dialogar com a fortuna crítica cabralina, há que se notar a falta do longo ensaio de José Guilherme Merquior "Nuvem civil sonhada". A leitura de Merquior, publicada em A astúcia da mímese (1972), rechaça as críticas que tendem a dicotomizar a poesia de Cabral e lê seus livros, de $O$ engenheiro ao "tríptico do Capibaribe", como uma solução de continuidade, afastando-se da ideia de uma fase formalista e outra social. Entendendo a poesia da poesia cabralina não apenas como uma consideração sobre a arte mas como investigação sobre a realidade, retifica tanto a imagem crítica vigente em Psicologia da composição (1947) quanto a ideia de que a poesia social representa uma superação da poesia da poesia, rumo a uma conquista da realidade. Assim, além daqueles críticos em que Waltencir de Oliveira diz se amparar por assinarem trabalhos que "trazem implícito 
algum argumento contrário à segmentação da obra de Cabral em duas vertentes" (p. 23), como é o caso de Antonio Candido, Adélia Bezerra de Meneses, Alfredo Bosi e Alcides Villaça, ele encontra outros precursores, seja entre os ausentes, seja, inclusive, entre aqueles com que estabelece um diálogo pelo avesso.

Mas esses e outros pontos cegos do livro não invalidam a contribuição que um trabalho corajoso e provocador como $O$ gosto dos extremos presta à fortuna crítica de João Cabral de Melo Neto.

\section{Referências}

BARBOSA, João Alexandre (2002). A poesia crítica de João Cabral. In: BARBOSA, João Alexandre. Alguma crítica. Cotia: Ateliê.

CAMPOS, Haroldo de (2004). O geômetra engajado. In: CAMPOS, Haroldo de. Metalinguagem e outras metas: ensaios de teoria e crítica literária. São Paulo: Perspectiva.

MELO NETO, João Cabral de. Duas águas. Rio de Janeiro: José Olympio, 1956.

MERQUIOR, José Guilherme (1972). Nuvem civil sonhada: ensaio sobre a poética de João Cabral de Melo Neto. In: MERQUIOR, José Guilherme. A astúcia da mímese: ensaio sobre lírica. Rio de Janeiro: José Olympio. 